\title{
Want to do better science? Admit you're not objective
}

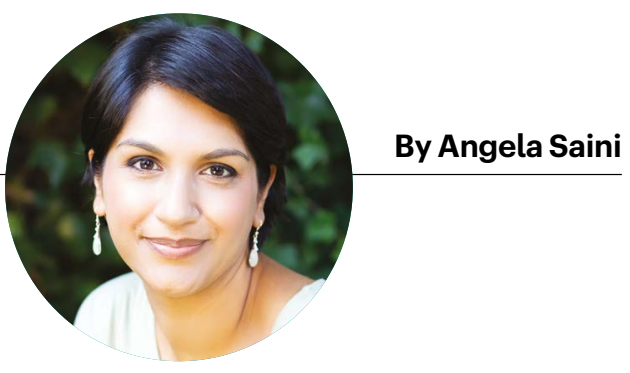

\section{When science is viewed in isolation from the past and politics, it's easier for those with bad intentions to revive dangerous and discredited ideas.}

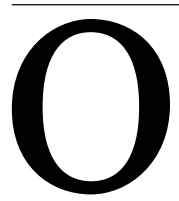
ne of the world's leading universities University College London (UCL) - has completed an inquiry into its support for the discredited pseudoscience of eugenics. Funds linked to Francis Galton, a racist who believed it was possible to improve the British population through selective breeding, and who founded the Eugenics Records Office at UCL in 1904, continue to line the university's coffers to the value of more than $£ 800,000$ (US\$1 million).

The inquiry's report, released on 28 February, recommended renaming lecture theatres and buildings bearing Galton's name and that of another prominent geneticist. Although this is welcome, it does not acknowledge just how much yesterday's mistakes survive in modern science.

As I found while writing my 2019 book Superior: The Return of Race Science, geneticists today rightly treat eugenics as a laughable proposition, and the concept of biological race - the belief that humans can be subdivided into distinct groups with meaningful differences between them - as easily debunked nonsense. But this ignores how these ideas manifest in the real world. They can only be truly understood as age-old intellectual threads, embedded in politics as much now as ever.

In failing to recognize that science can be political, the scientific community allows the resurrection of dangerous ideas. Acting as if theories - especially those about humans - exist in cultural or political vacuums is a ridiculous fallacy.

The UCL inquiry was prompted in part by 2018 revelations that a now-former honorary fellow had been booking meeting space for secretive conferences discussing race and eugenics. Many people - even members of the inquiry committee - are concerned that the investigation did not go far enough in connecting the pseudoscience of the past with ongoing attempts to keep that pseudoscience alive.

In the same month that UCL released its report, news broke that Dominic Cummings, a self-proclaimed science enthusiast and special adviser to the UK prime minister, had hired an aide who espouses eugenicist views. Now resigned, Andrew Sabisky had suggested compulsory contraception to halt the growth of a "permanent underclass".

When a survey conducted as part of the UCL inquiry asked staff and students whether "we should separate science and politics", it found agreement among higher percentages of those in the sciences and engineering than

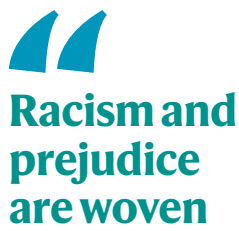

into the structures in which we all live and work - and into us."

Angela Saini is a science journalist and broadcaster based in London. www.angelasaini. co.uk in the social sciences and history. In my coverage of the inquiry, I've seen that it was not the university's biologists, but its humanities scholars - including curator Subhadra Das and historian Joe Cain - who forced their workplace to confront a sordid history that some geneticists had been willing to overlook.

"If the past is to be called upon to legitimize the present, as it so frequently is, then the veracity of such a past has to be continuously vetted," writes Romila Thapar, a historian at Jawaharlal Nehru University in New Delhi. Those who seek to bring back eugenics prefer to gloss over the past and treat the concept as a purely scientific proposition. This is made easier by scientists who are willing to separate science from politics, even when - as with eugenics - it was inherently political to begin with.

The UCL survey also revealed that members of the university community who are disabled or from minority ethnic backgrounds are more likely to feel that the legacy of eugenics is still present than are those who are white and not disabled. The people on the receiving end of the worldview that drove eugenics understand how alive it remains.

Scientists who imagine that bias lies in others, not themselves, fail to recognize that to live in the world today is to be drip-fed assumptions and prejudices that guide our thoughts and actions. If it were any other way, the demographics of academia would be more equitable, and the current strain of genetic determinism in governments wouldn't be possible. Racism and prejudice are woven into the structures in which we all live and work - and into us.

A lack of education means we fail to draw these links. At a philosophy festival last September, I spoke about non-European cultures and their contributions to science and mathematics. One scientist remarked that he had no need to know about what had been done in 'bongo bongo' land. The audience was shocked; I was disappointed. He was a product of a system that had not taught him that he needed to know better. It is this system we need to fix.

Scientists rarely interrogate the histories even of their own disciplines. When I studied engineering at university, I was expected to write just one essay on ethics in four years. No wonder that new technologies perpetuate racial and gender stereotypes, or that automated facial recognition struggles to identify people with darker skin.

The best research is done not when we pretend that we are perfectly objective, but when we acknowledge that we are not. The UCL inquiry report recommends that students and staff be exposed to the history of eugenics, and that students be encouraged to value the history of their own fields. I would go further. Scientists need both history and the social sciences to develop the intellectual tools to think critically about their research and how it affects society. This isn't just helpful - it's vital. 